\title{
Marketing Communication Drivers of Adoption Timing of a New E-Service among Existing Customers
}

\author{
Remco Prins and Peter C. Verhoef
}

\begin{tabular}{|l|l|}
\hline \multicolumn{2}{|l|}{ ERIM REPORT SERIES RESEARCH IN MANAGEMENT } \\
\hline ERIM Report Series reference number & ERS-2007-018-MKT \\
\hline Publication & March 2007 \\
\hline Number of pages & 40 \\
\hline Persistent paper URL & \\
\hline Email address corresponding author & prins@few.eur.nl \\
\hline Address & Erasmus Research Institute of Management (ERIM) \\
& RSM Erasmus University / Erasmus School of Economics \\
& Erasmus Universiteit Rotterdam \\
& P.O.Box 1738 \\
& 3000 DR Rotterdam, The Netherlands \\
& Phone: + 31104081182 \\
& Fax: $\quad+31104089640$ \\
& Email: info@erim.eur.nl \\
& Internet: www.erim.eur.nl \\
\hline
\end{tabular}

Bibliographic data and classifications of all the ERIM reports are also available on the ERIM website: www.erim.eur.nl 


\section{ERASMUS RESEARCH INSTITUTE OF MANAGEMENT}

\section{REPORT SERIES}

\section{RESEARCH IN MANAGEMENT}

\begin{tabular}{|l|l|}
\hline \multicolumn{2}{|l|}{ ABSTRACT AND KEYWORDS } \\
\hline Abstract & $\begin{array}{l}\text { The study investigates the effects of direct and mass marketing communications on the adoption } \\
\text { timing of a new e-service among existing customers. The mass marketing communications } \\
\text { concern both specific new service advertising and brand advertising from both the focal supplier } \\
\text { and competitors. Using a split-hazard approach, the authors account for the fact that a significant } \\
\text { part of the customer base will never adopt the new e-service. The empirical results show that } \\
\text { service advertising shortens the time to adoption, even when it is initiated by competitors. }\end{array}$ \\
\hline Free Keywords & $\begin{array}{l}\text { New product adoption, Competitive advertising, Hazard model, E-services, Telecommunications } \\
\text { Availability }\end{array}$ \\
$\begin{array}{l}\text { The ERIM Report Series is distributed through the following platforms: } \\
\text { Academic Repository at Erasmus University (DEAR), DEAR ERIM Series Portal } \\
\text { Social Science Research Network (SSRN), SSRN ERIM Series Webpage } \\
\text { Research Papers in Economics (REPEC), REPEC ERIM Series Webpage }\end{array}$ \\
\hline Classifications & $\begin{array}{l}\text { The electronic versions of the papers in the ERIM report Series contain bibliographic metadata } \\
\text { by the following classification systems: } \\
\text { Library of Congress Classification, (LCC) } \underline{\text { LCC Webpage }} \\
\text { Journal of Economic Literature, (JEL), JEL Webpage } \\
\text { ACM Computing Classification System CCS Webpage } \\
\text { Inspec Classification scheme (ICS), ICS Webpage }\end{array}$ \\
\hline
\end{tabular}




\title{
Marketing Communication Drivers of Adoption Timing of a New E-Service Among Existing Customers
}

\author{
Remco Prins $^{1}$ and Peter C. Verhoef
}

October 2006

\footnotetext{
${ }^{1}$ Remco Prins is a PhD Candidate at the Erasmus Research Institute of Management, Erasmus University Rotterdam, Office H9-09, P.O. Box 1738, NL-3000 DR Rotterdam, The Netherlands, Phone +31 10408 8943; E-mail: prins@few.eur.nl. Peter C. Verhoef is a Professor of Marketing at the Faculty of Economics, University of Groningen, The Netherlands; E-mail: p.c.verhoef@rug.nl. The authors acknowledge the data support of a large Dutch telecom operator and BBC. They also gratefully acknowledge technical support by Govert Bijwaard. They thank Ruth Bolton, Marnik Dekimpe, Bas Donkers, and Richard Paap for their helpful comments on an earlier version of this manuscript.
} 


\title{
Marketing Communication Drivers of Adoption Timing of a New E-service among Existing Customers
}

\begin{abstract}
This study investigates the effects of direct and mass marketing communications on the adoption timing of a new e-service among existing customers. The mass marketing communications concern both specific new service advertising and brand advertising from both the focal supplier and competitors. Using a split-hazard approach, the authors account for the fact that a significant part of the customer base will never adopt the new e-service. The empirical results show that service advertising shortens the time to adoption, even when it is initiated by competitors.
\end{abstract}

Keywords: new product adoption, competitive advertising, hazard model, e-services, telecommunications. 
Successful new product/service introductions are very important for a firm's long-term performance. This especially holds for industries where firms heavily invest in technologies, such as mobile networks, under the premise that firms would be able to introduce new services using these technologies. For example, in Europe, telecom firms invested heavily in licenses for UMTS networks, paying a total amount of 109 billion euros to the owners (i.e., the government) of these networks, hoping that new 3G-services would cause the saturated mobile telecom market to grow again (The Economist 2004). Soon it became clear that the expectations about the UMTS technology were too high and that the actual roll-out of $3 \mathrm{G}$ services would take several years longer. As a consequence, market values of telecom firms dropped considerably (Van Damme 2002). Clearly, in order to get return on this type of technological investments, the new services based on the new technology should be successfully introduced. To achieve this, service providers have to formulate an introduction strategy that both focuses on existing customers and potential new customers. Existing customers may be the most important target group for newly introduced products or services, as they may be more likely to adopt the innovation due to their positive attitude towards the firm.

There is a large research stream in the marketing literature on new product adoption or trial by consumers (Meuter et al. 2005; Rogers 1995; Steenkamp and Gielens 2003). An important characteristic of this research stream is that it usually studies the adoption of new products or services in the total market, which consists of both existing customers and noncustomers. So far, researchers did not study the adoption of new products or services among existing customers only. Moreover, many companies now consider their existing customers as assets, which is reflected in the increasing importance of customer management in many industries (e.g. Boulding et al. 2005). From a customer management perspective, the crossselling of new services to current customers can be a good strategy to increase the value of the customer base. If current customers adopt the new service, their customer lifetime value (CLV) should increase (Bolton, Lemon, and Verhoef 2004; Gupta, Lehmann, and Stuart 2004; Hitt and Frei 2002; Hogan et al. 2002; Rust, Zeithaml, and Lemon 2000), as long as the new service does not fully replace an existing one. Not only the adoption itself but also the timing of adoption is relevant in terms of a higher CLV, because increased cash flows from a new product adoption occur earlier in the relationship, and prices of new services often are higher in the early stages of the product lifecycle. In this study we will investigate marketing communication drivers of the adoption timing of a new e-service among existing customers ${ }^{\mathrm{i}}$. In doing so, we aim to contribute to both the adoption and customer management literature. 
However, first it is important to consider the difference between cross-buying or addon buying of services and adoption of a new service among existing customers, as one might argue that new service adoption and cross-buying of additional services is the same, because it both concerns relationship expansion through buying more services (e.g. Verhoef, Franses, and Hoekstra 2001). There are, however, some fundamental differences. First, cross-buying pertains to services that are already mature and known to the customer, whereas new service adoption involves products or services that are new-to-the-world. This newness makes it a different buying decision, as there is much more uncertainty about the characteristics and the usefulness of the new service. Second, cross-buying may also imply switching a service (e.g. a car insurance) from a competitor to the focal firm, whereas new product adoption by definition implies buying a newly introduced service which is not yet purchased from competitors. Third, whereas cross-selling of services mainly focuses on existing customers through for example direct mailings and telemarketing (e.g. Verhoef, Franses, and Hoekstra 2001), the introduction of new services both concerns the introduction to the existing customers, and to the total market. This causes large differences in the marketing communications that are used. Whereas cross-selling strategies mainly use below-the-line advertising, new product introductions may use both mass marketing communications and below-the-line advertising.

We contribute to the adoption literature as follows. First, this is the first study that solely considers the adoption timing decision among existing customers. Second, we broaden the scope of studied marketing communication drivers. Adoption studies generally consider the impacts of innovation characteristics, such as relative advantage, ease of use, risk, complexity, and consumer characteristics such as demographics and innovativeness (e.g. Arts, Frambach, and Bijmolt 2005; Manning, Bearden, and Madden 1995; Steenkamp and Burgess 2002). Recently, Steenkamp and Gielens (2003) included (time-varying) marketing and communication efforts, such as advertising and promotions, as predictors of new product adoption in a consumer packaged goods (CPG) context. However, attention to the impact of marketing communication efforts on new product or service adoption remains limited. Studies have generally ignored: (1) the impact of individual oriented marketing communication efforts (or direct marketing communications), such as direct mailings and e-mails; (2) the differential impact of marketing communication efforts specifically focussed on the new product/service and marketing communication efforts at the brand/company levelii; and (3) the impact of competitive marketing communication both at the new product/service and brand/firm level. 
We contribute to the customer management literature as follows. First, new product adoption as a driver of customer equity has been almost completely ignored. For example, Bolton, Lemon, and Verhoef (2004) only focus on customer retention, service usage, and cross-buying as components of CLV in their CUSAMS-framework. Hogan and colleagues (2002) merely conceptually acknowledge the importance of new product adoption for customer profitability and CLV. Empirically, Hogan, Lemon, and Libai (2003) relate service adoption behavior to CLV and state that defecting new product adopters have a significant negative impact on customer equity because of negative word of mouth. Recently, Kamakura, Kossar, and Wedel (2004) developed a methodology to identify new product adopters for cross-selling purposes, using past behavioral data as predictors, but they do not theoretically focus on drivers of new service adoption. Second, studies on the predictors of customer behavior mainly consider individual oriented- or customer-specific marketing interventions, also referred to as below-the-line advertising (Venkatesan and Kumar 2004). In this study, we include not only customer-specific marketing interventions, but also above-the-line advertising expenditures over time, which do not vary across customers. As noted by Bolton, Lemon, and Verhoef (2004), advertising is generally associated with mass marketing, but Ambler and colleagues (2002) argue that brand advertising may increase the value of existing customers as well. Empirical evidence for this effect from advertising data remains scarce. Third, most studies in the customer management area do not include competitive instruments, though understanding customer responses to competitive actions is essential (Keiningham, Purkins-Munn, and Evans 2003). We therefore explicitly take into account the effect of competitive advertising on individual customer adoption.

The remainder of this article is organized as follows: We first discuss our conceptual model, which we apply in the context of customer adoptions of a new e-service. Subsequently, we discuss our model to explain adoption timing. It is important to note, that we use a split-hazard model, which jointly models antecedents of the adoption probability and adoption timing. In the next section, we present the empirical results and key findings pertaining to the impact of various types of mass advertising on adoption timing and the different effects of customer-specific antecedents on adoption probability and timing. In addition, we report some significant interaction effects between mass marketing efforts and customer behavior. We conclude with a discussion of the findings, implications, and limitations of our study. 


\section{Conceptual Model and Hypotheses}

We display our conceptual model in Figure 1. In this model, we study the effect of marketing communication efforts on the adoption timing of a new service. We define adoption timing as the time between the introduction and the adoption of the new service (Steenkamp and Gielens 2003). In this context adoption is defined as the actual buying of the new service by an existing customer. In our empirical model we will consider this adoption timing to be conditional on adoption. We will discuss this issue more elaborately in our methodology section. In our model, the main focus is on the effect of marketing communication efforts, as many studies in the new product diffusion literature already showed that marketing efforts can have a significant effect on adoption rates at the aggregate level (Bass, Krishnan, and Jain 1994; Horsky and Simon 1983; Kalish 1985; Simon and Sebastian 1987). We consider three groups of marketing communication variables, that potentially explain adoption timing: (1) Direct marketing communication efforts concerning the new service to existing customers (DMC); (2) Mass marketing communication efforts (MMC) (i.e. advertising) at the new service level and at the brand/firm level; and (3) Competitive mass marketing communications (CMMC) at the new service level and at the brand/firm level. We also include a set of covariates to control for customer specific effects: (1) relationship characteristics (i.e. relationship age, service usage) and (2) customer characteristics (i.e. age, gender, innovativeness).

$$
<\text { Figure } 1 \text { about here }>
$$

\section{Direct Marketing Communication}

DMC mainly focuses on directly influencing buying behavior of existing customers, by for example providing attractive offers, and are essentially transaction-oriented (Rust and Verhoef 2005). The effect of DMC on customer buying behavior only recently gained some attention in the academic marketing literature. Verhoef (2003) shows that DMC increases customer share. Venkatesan and Kumar (2004) report initial positive effects for reasonable amounts of DMC on purchase frequency, which become negative for large amounts of DMC (inverted U-shaped effect). Verhoef, Franses and Hoekstra (2001) report positive effects of $\mathrm{DMC}$ on cross-buying. In the adoption literature attention for DMC is lacking, because of its focus on adoption behavior in the total market. Steenkamp and Gielens (2003) study other below-the line actions, such as promotions, and show that these positively affect individual trial probabilities for CPGs. Together, these studies suggest that DMC directly points attention to the new service among existing customers, which may have a direct impact on their adoption behavior with respect to this new service. Hence, we hypothesize: 
$H_{1}$ : Direct marketing communication efforts shorten customers' time to adoption.

\section{Mass Marketing Communication}

Within the innovation diffusion/adoption literature, advertising is considered as an important marketing tactic to diffuse the innovation in the market (e.g. Bass, Krishnan, and Jain 1994; Kalish 1985). On the individual consumer level, Steenkamp and Gielens (2003) show that mass advertising accelerates adoption among individual consumers. Generally, advertising may create awareness and knowledge of the new service among both existing customers and other consumers. Next to awareness, advertising may also aim to inform potential adopters about the advantages of the new service, which may induce adoption. All of this will be predominantly accomplished through advertising that specifically mentions the new service: new service advertising. Given the strong empirical results in the innovation/adoption literature, new service advertising will most likely shorten adoption timing. However, as noted earlier, this literature studies all consumers, and does not distinguish between existing customers and non-customers.

Customer management researchers investigating antecedents of customer behavior usually do not include mass advertising efforts as a potential antecedent. A notable exception is the customer equity framework developed by Rust, Zeithaml and Lemon (2000), who acknowledge the effect of branding on customer equity. However, in their modeling framework they both include existing customers and non-customers. The absence of the effect of mass advertising is explained by two reasons. First, from a data perspective, mass advertising data are not collected in customer databases, as they are only available at an aggregate weekly or monthly level. As a consequence, time series data on customer behavior are required (i.e. per month) to match these aggregated advertising data. These data should be integrated with customer database data. Second, from a theoretical perspective, researchers have assumed that behavior of existing customers is predominantly affected by company behavior within the customer relationship. Advertising mainly plays a role in attracting new customers (e.g. Bolton, Lemon, and Verhoef 2004). This might be true for behavior such as customer retention and cross-buying. However, for newly introduced services, awareness should also be created among existing customers and information on this new product should also be communicated to existing customers. This might be done by DMC. Additionally, existing customers are likely to be confronted with mass advertising promoting the new service, which should at least have some effect on customer behavior following the noted diffusion research. Based on the above discussion we hypothesize: 


\section{$\mathrm{H}_{2}$ : $\quad$ Service advertising shortens customers' time to adoption.}

Firms will not only advertise newly introduced services, but they will also continue their brand focused advertising efforts. This brand advertising mainly aims to increase brand awareness, to improve brand attitudes and to impact purchasing behavior, such as brand choice (e.g. Lodish et al. 1995; Rossiter and Percy 1997; Vakratas and Ambler 1999). The question is whether this brand advertising will also positively affect adoption of newly introduced services. One argument in favor of an effect is that brand advertising creates a more positive attitude towards the brand, which may positively affect the attitude towards the newly introduced service, which in turn may positively affect adoption behavior. In the same vain, for example, Verhoef, Franses, and Hoekstra (2002) show that customers being more committed to the firm are more likely to buy more services. The size of this effect will, however, be significantly smaller than the effect of specific service advertising, which directly

aims to improve awareness for the new service and attitudes towards the brand. Hence, we hypothesize:

$H_{3}$ : $\quad$ Brand advertising shortens customers' time to adoption.

$H_{4}$ : $\quad$ Service advertising shortens customers' time to adoption more than does brand advertising.

\section{Competitive Mass Marketing Communication}

New services are usually not introduced by a single firm in the market. Competitors may introduce a similar service as well. These competitors will also advertise their new service to stimulate adoption. Within the diffusion literature there has been particular attention for the effect of this competitive advertising. One might be inclined to think that competitive service advertising would negatively affect the adoption of the new service among existing customers of the focal supplier. However, within the diffusion literature there is ample evidence that competitive new service advertising may work positively. It may in fact accelerate individual adoption through the market-making effect; i.e., the advertising efforts of all competitors will increase the penetration rate of new services (Krishnamurthy 2000; Krishnan, Bass, and Kumar 2000). Because of this higher penetration rate, competitors will benefit from one another's advertising efforts pertaining to the new service, particularly in new markets with relatively few competitors (Mahajan, Sharma, and Buzzel 1993). Hence, we hypothesize:

$H_{5}$ : Competitive service advertising shortens customers' time to adoption. 
Like the focal supplier, competitors may also continue their brand advertising. Similar to the focal suppliers' brand advertising, competitive brand advertising aims to create competing brand awareness, to enhance positive competitive brand attitudes, and to impact competing brand buying behavior. A possible consequence of competitive brand advertising is the enhancement of positive competitive brand attitudes among existing customers. It may perhaps also decrease brand attitudes of the focal suppliers. This might negatively impact adoption. However, so far, evidence for these described paths of effects is almost absent in the marketing literature. In their customer equity model, Rust, Zeithaml and Lemon (2000) assume that when a firm increases its advertising, it creates higher perceived brand equity through increased brand awareness and positive attitude creation, which should lead to higher choice shares for the focal supplier and to lower choice shares for competing suppliers. Whether such an effect might also occur for new service adoption is an empirical question. However, for now we will formulate a hypothesis that is in line with our reasoning:

$H_{6}$ : Competitive brand advertising lengthens customers' time to adoption.

\section{Interaction Effects Between Marketing Communication Efforts}

In addition to the direct effects of these explanatory variables, we also explore the interaction effect between DMC and MMC. Previous research (e.g. Naik and Raman 2003; Schultz, Tannenbaum, and Lauterborn 1993) points to a synergy between different marketing communications types (i.e. DMC and MMC), which should be reflected in a positive interaction effect. This positive interaction effect may for example occur, as MMC, creating awareness and positive attitudes for the new service, may increase the effect of DMC. We have no reason to expect that there will be differences in these effects between service and brand advertising.

$H_{7}$ : $\quad$ There is a positive interaction effect between DMC and service advertising.

$H_{8}: \quad$ There is a positive interaction effect between DMC and brand advertising.

\section{Covariates}

Based on prior research in the adoption and customer management literature, we include two groups of covariates in our model: relationship characteristics and customer characteristics.

We consider the relationship's length and depth as relationship characteristics (Bolton, Lemon, and Verhoef 2004). Several researchers have pointed out that relationship length may affect customer behavior (Dwyer, Schurr, and Oh 1987; Hitt and Frei 2002). This relationship 
may, however, be nonlinear (Bolton, Lemon, and Verhoef 2004; Hitt and Frei 2002). Relationship depth, often referred to as usage intensity or category usage, generally is considered as an antecedent of trial or adoption probability (e.g. Steenkamp and Gielens 2003). Consumers who display high category usage levels have a greater category need and therefore a higher trial probability for a new product within that category (Gatignon and Robertson 1991). Again, there may be some nonlinearities in this relationship due to customer lifecycle effects (Bolton, Lemon, and Verhoef 2004).

The included relationship characteristics are not only of interest because of possible direct effects on adoption timing. There might also be some interaction effects between relationship characteristics and communication efforts. Empirical research by Rust and Verhoef (2005) indicates significant heterogeneity of responses to marketing interventions that may be related to relationship characteristics. In particular, we explore the interactions between relationship age on the one hand and DMC, (competitive) service advertising, and (competitive) brand advertising on the other hand. Although the investigation of these interactions is not the primary objective of this study, we believe it might provide valuable insights on the effects of marketing communication efforts on adoption, which might be studied in-depth in other studies.

The customer characteristics we include as covariates are: age, gender, and domainspecific innovativeness. These customer characteristics likely play an important role in the adoption probability and timing of individual customers (Arts, Frambach, and Bijmolt 2005). For example, in general, early adopters tend to be younger (Meuter et al. 2005; Rogers 1995). Customer innovativeness is also often considered as an important antecedent of new product adoption. Most studies (e.g. Im, Bayus, and Mason 2003; Midgley and Dowling 1993; Steenkamp, Ter Hofstede, and Wedel 1999) focus on innate innovativeness as an individual trait that can be generalized over product categories and find that innovative persons have a higher tendency to adopt new products and adopt them faster. Citrin and colleagues (2000) and Goldsmith, Freiden, and Eastman (1995) show that domain-specific innovativenesswhich reflects the consumer's tendency to try the latest innovations in a product categoryhas a stronger relationship with individual adoption behavior than does innate innovativeness. Our data provide information on the adoption of a previously introduced new service, which may be an indicator of domain-specific innovativeness. Hence, we control for domain-specific innovativeness in our model. 


\section{Data Description}

Our empirical study focuses on the adoption process of a new mobile e-service in the Dutch consumer market, introduced in 2002 by one of the leading Dutch mobile telephone providers. The new service uses GPRS (General Packet Radio Service) technology to give subscribers access to a range of Web sites specifically designed for mobile telephone use. For our empirical analyses, we employ the service provider's customer database, from which we gather monthly data on mobile subscribers, starting with the introduction date of the new service. These data include information on demographics, usage levels of various services, relationship characteristics, and marketing communication efforts by the provider. After the introduction of the new e-service, every customer could subscribe to it, in addition to their regular subscription with the mobile telephone operator. For each adopting customer, we know the first usage date of the new service, which enables us to determine the individual adoption times for those customers who adopted the new service during the observation period.

We have chosen to study adoption timing in this specific industry, for this specific company, and this specific service for the following reasons. First, the telecom industry is known to continuously collect data on customer behavior in large databases, which allows us to study actual adoption behavior instead of reported or intended adoption behavior for existing customers. Second, the telecom industry has been a subject of research in prior adoption/diffusion and customer management research studies (i.e. Bolton 1998; Bolton and Lemon 1999; Simon and Sebastian 1987). Third, this industry is very important in today's economies and is continuously introducing new services. Fourth, the introduction of this type of services is managerially very relevant, as these firms introduce these new services to get returns on their investments in technological networks. Fifth, this company was the first in the Netherlands to introduce this service. Hence, the introduced service is fully new to the market. Finally, more from a practical standpoint in doing successful collaborative research, there is a requirement to closely work with firms, which was possible with this firms due to earlier positive experiences.

\section{Sample}

For our analyses, we randomly selected a total of 6,000 mobile subscribers from the provider's customer database who were current customers at the start of the observation period, which ran from August $2002(\mathrm{t}=1)$ through August $2004(\mathrm{t}=25)$. The start of the observation period is marked by the introduction date of the new service. By the end of the 
observation period, the number of existing customers adopting the new service is rapidly declining (see Figure 2). Thus, we can expect that the chosen observation period will capture the effects on adoption timing for most existing customers. Although all customers were with the provider at the start of the observation period, a total of 910 left the provider before the end of the period. To avoid a selection bias, we did not exclude these customers from our sample $\mathrm{iii}^{\mathrm{ii}}$.

\section{$<$ Figure 2 about here $>$}

We were confronted with the issue of a relatively small adoption rate, which is not uncommon for multigenerational products or services, because the users of the older technology will not immediately adopt the new one (Mahajan and Muller 1996; Pae and Lehmann 2003). It may take a significant amount of time before the diffusion of a new product really takes off (Golder and Tellis 1997; Tellis, Stremersch, and Yin 2003). Because we were particularly interested in the adoption of the new service but only a small portion of customers had adopted the service before September 2004, we over-sampled these adopting customers. In our procedure, we over-sampled the number of adopters, so that approximately half the sample adopted the new service during the observation period, which gave us 3,431 adopting customers, or 53\% of the sample. Donkers, Franses, and Verhoef (2003) demonstrate, oversampling a rare event in binary choice models does not affect the parameter estimates or their standard errors, as long as the over-sampling is not accompanied by stratified sampling on the independent variables. So far, there is no statistical research showing that over-sampling has an effect on the parameter estimates and standard errors of the split-hazard model. Hence, it is not clear what the effect of over-sampling is on the split hazard model results. We therefore estimated models with a smaller fraction of adopters. These models showed similar results in terms of sign and significance of the coefficients. However, models with few adopters have convergence problems. We therefore also estimated normal hazard models with different fractions of adopters. These results show that the sign of the coefficients do not change. For rather small fractions, however, a smaller number of variables become significant due to sample size effects. These additional analyses provided us with sufficient confidence in our estimation results.

\section{Measurements}

Time to Adoption. For each month in our observation period, we observed whether a customer had adopted the new service. The time to adoption for each customer represents the 
time elapsed in months since the introduction of the e-service. We use the individual time to adoption as our observed dependent variable.

Marketing Communication Variables. During the observation period, the provider selected customers who would receive an individual offer by telephone to adopt the new service. Our data indicate whether and when each customer received an offer call from the provider. We operationalize these data by including a dummy variable that indicates the month(s) in which the customer received the offer. Some customers who did not respond to the first offer were subsequently selected for a second offer. Although we recognize that the provider may have selected only those customers who were most likely to adopt in the first place, which would cause an endogeneity problem, we believe that by incorporating all possible selection criteria into our model, we can avoid serious problems in estimating the effect of DMC (Franses 2005; Shugan 2004).

We use data pertaining to monthly advertising expenditures to account for advertising effects on adoption timing. We retrieve these advertising data from $\mathrm{BBC}$, a Dutch division of Nielsen Media Research International. Furthermore, we distinguish among service advertising, brand advertising, competitive service advertising, and competitive brand advertising for television, radio, print, outdoor, and cinema. We define service advertising as the provider's monthly expenditures (in millions of euros) on advertising that explicitly features the new e-service. In all cases, these advertisements mention the brand name of the provider as well, but the main focus was on the new service. We define brand advertising as the provider's expenditures on advertising not directly related to the new e-service.

Although the e-service was new to the market at the time of introduction by the provider, six months later, one of its competitors launched a similar service. Therefore, we include competitive service advertising, or the competitor's advertising that explicitly features a similar e-service. Again, the competitor mentioned its brand name in all of these advertisements. Finally, we include competitive brand advertising, which is all competitors' advertising that is unrelated to any similar e-services. To allow for possible lagged advertising effects, we also include all advertising expenditures in the previous month.

Covariates. As noted, we included relationship age and service usage as covariates. We define relationship age as the number of years the customer had been with the provider at $t=1$, the beginning of the observation period. To measure the service usage, we compute the average monthly amount spent by each customer over his or her total customer lifetime prior 
to the beginning of the observation period. Thus, service usage does not include usage of the newly introduced e-service.

The customer demographics we control for are gender and age. We set the gender dummy to zero for male customers, and we define the age variable as the customer's age in years at the start of the observation period, so that it is fixed over time. As a proxy for the domain-specific innovativeness of each customer with respect to mobile e-services, we include a dummy variable that indicates the adoption and use of a prior generation mobile eservice, which had been introduced several years before.

In Table 1, we summarize and describe all our included variables.

$<$ Table 1 about here $>$

\section{Methodology}

Adoption studies that consider adoption as a discrete event use a logit or probit-like model to assess the impact of independent variables on adoption (e.g. Meuter et al. 2005), whereas those investigating adoption timing tend to use a hazard model (e.g. Steenkamp and Gielens 2003). The hazard model makes the assumption that, eventually, every consumer will adopt the new product. Especially for products and services with greater technological complexity, there will be a significant group of consumers who will never adopt. Theoretically, this issue as been pointed to as innovation resistance, reflected in rejecting the new service, opposing against the new service, or postponing the adoption of the new service (e.g. Bagozzi and Lee 1999; Mittelstaedt et al. 1976; Ram and Sheth 1989; Szmigin and Foxall 1998) This innovation resistance may for example be caused by the fact that consumers are comfortable with the current situation, do not see the advantage of the new service, or consider it as a very risky innovation. Sheth (1981) indeed concludes that consumers resisting innovations tend to be different from consumers not resisting innovations.

The notion that a group of customers will probably never adopt the new service has important implications when studying the antecedents of adoption timing. Not only are these consumers unaffected by the time elapsed after the introduction of the product, we also assume that they are 'immune' to any marketing efforts. In other words, the probability of adoption for these consumers is 0. A traditional hazard approach does not account for this group, because it imagines all consumers as 'at risk' for adoption after the product's introduction. In practice, we cannot observe whether a consumer belongs to the immune group, but we can estimate the probability of eventual adoption by each consumer using available customer characteristics. 
The econometric model accounting for the problem - that a significant portion of the subjects will never adopt - emerges through the split-hazard approach, developed by Schmidt and Witte (1989) and has been applied in various contexts, including new product adoption (e.g. Chandrashekaran and Sinha 1995; Dekimpe et al. 1998; Kamakura, Kossar, and Wedel 2004; Sinha and Chandrashekaran 1992). Following this methodology, we apply a splithazard approach to model both the adoption probability and the adoption timing of the new service by existing customers. The time to adoption for individual $\mathrm{i}$, denoted by $T_{i}$, thus is a random variable with a cumulative distribution function $F(t)$ and density $f(t)=F^{\prime}(t)$. The probability that adoption has not yet occurred at time $\mathrm{t}$ is provided by the survivor function $S(t)=1-F(t)$. The hazard rate $h(t)=f(t) / S(t)$ can be defined as the conditional likelihood that adoption will occur at time $t$, given adoption has not occurred yet. We can only observe adoption for those consumers who adopted within the period of observation $[0, \mathrm{~T}]$; those who do not adopt before time $\mathrm{T}$ will either be censored and adopt at some time beyond $\mathrm{T}$ or never adopt at all. The split-hazard model enables us to estimate simultaneously the probability of eventual adoption and the time to adoption. We include a dummy variable that indicates adoption by the end of the month in the hazard part of our model as the failure indicator. Customers are considered at risk of adoption as long as they have not adopted the new service. Those customers who left the provider during the observation period can be included in the analysis only for the time periods in which they remained with the company.

We model adoption timing as a hazard function of both time-varying marketing communication efforts, and the time-invariant covariates, i.e. relationship characteristics and customer characteristics. The baseline hazard function follows a prescribed distribution and captures the longitudinal regularities in adoption time dynamics, separate from the effects of the covariates. In other words, it captures the effect of the time elapsed since the introduction of the new product. The parametric form we use for our hazard function is the complementary $\log$-log model, which is particularly useful when data from discrete time intervals are used for a continuous underlying adoption process, because the estimates of the model do not depend on the length of the time intervals (Allison 1982; Van den Bulte and Lilien 2001). To account for (nonlinear) time dependencies of the baseline hazard rate, we include a time trend variable and the squared time trend in the hazard part of our model. Higher-order transformations result in significant coefficients but would capture too much of the effects of the time-varying variables, such as advertising effects. Therefore, we only allow for a first- and second-power time dependency of the baseline hazard in our model. 
The hazard part of our model, including all explanatory variables, can be represented as follows:

$$
\begin{gathered}
h_{i t}=1-\exp \left[-\exp \left(\beta_{0}+\beta_{1} \cdot t+\beta_{2} \cdot t^{2}+\beta_{3} \cdot D M C_{i t}+\beta_{4} \cdot S A_{t}+\beta_{5} \cdot S A_{t-1}+\beta_{6} \cdot B A_{t}\right.\right. \\
(1)+\beta_{7} \cdot B A_{t-1}+\beta_{8} \cdot C S A_{t}+\beta_{9} \cdot C S A_{t-1}+\beta_{10} \cdot C B A_{t}+\beta_{11} \cdot C B A_{t-1}+\beta_{12} \cdot R A_{i}+\beta_{13} \cdot R A_{i}{ }^{2} \\
\left.\left.+\beta_{14} \cdot S U_{i}+\beta_{15} \cdot S U_{i}^{2}+\beta_{16} \cdot \text { Age }_{i}+\beta_{17} \cdot \operatorname{Age}_{i}{ }^{2}+\beta_{18} \cdot \text { Gend }_{i}+\beta_{19} \cdot \text { Innov }_{i}\right)\right] .
\end{gathered}
$$

Simultaneously, we estimate the unobserved probability of eventual adoption for every individual customer, which we denote by $p_{i}$. We model the probability of eventual adoption as a logit function of time-invariant customer characteristics and relationship characteristics:

$$
\begin{aligned}
& p_{i}=1 /\left[1+\exp \left(\gamma_{0}+\gamma_{1} \cdot R A_{i}+\gamma_{2} \cdot R A_{i}^{2}+\gamma_{3} \cdot S U_{i}+\gamma_{4} \cdot S U_{i}^{2}+\gamma_{5} \cdot \text { Age }_{i}\right.\right. \\
& \left.\left.+\gamma_{6} \cdot \text { Age }_{i}{ }^{2}+\gamma_{7} \cdot \text { Gend }_{i}+\gamma_{8} \cdot \text { Innov }_{i}\right)\right] .
\end{aligned}
$$

The log-likelihood function of our total model (including Equations 1 and 2 ) is as follows:

$$
L L=\sum_{i=1}^{N} d_{i} \cdot \ln \left[p_{i} \cdot h_{i t} \cdot S_{i t-1}\right]+\left(1-d_{i}\right) \cdot \ln \left[\left(1-p_{i}\right)+p_{i} \cdot S_{i t}\right]
$$

where

$h_{i t}=$ hazard rate from Equation 1,

$p_{i}=$ probability of eventual adoption from Equation 2,

$d_{i}=$ censoring indicator ( 1 if observed; 0 if censored), and

$S_{i t}=$ survival rate.

For observed adoptions, the censoring indicator $d_{i}$ equals 1 . The contribution to the likelihood function by consumer $\mathrm{i}$ at time $\mathrm{t}$ will be the probability that he or she will eventually adopt, as given by $p_{i}$, multiplied by the conditional probability of adoption at $\mathrm{t}$, as given by the hazard rate $h_{i t}$, and by the probability that he or she has not adopted before $\mathrm{t}$, as given by the survival rate $S_{i t-1}$. Censored observations, for which $d_{i}$ is 0 , belong to either the non-adopters, with probability $\left(1-p_{i}\right)$, or those who will eventually adopt but have not yet, given by the terms $p_{i} \cdot S_{i t}$. To obtain the coefficients for every explanatory variable, we use maximum likelihood estimation in STATA version 8.2. 


\section{Results}

To assess whether the split-hazard model is required, as we assume that a significant part of the existing customers will probably never adopt the new e-service, we also estimated an ordinary proportional hazard model. Note that these models are nested. When we compare the fit of our split hazard model to the proportional hazard model, it shows that our model has a significantly better fit, according to the likelihood-ratio test: $\chi^{2}(9)=27.546(p<0.01)$. Also, the AIC-statistic of the split hazard model is smaller (27,229.89 vs. 27,239.44), which indicates a better fit. The BIC-statistic does not show an improvement, which would imply that the split hazard model does not do a better job in explaining adoption timing than the ordinary hazard model does. Note that BIC penalizes more complex models more heavily than the AIC does. However, based on the discussed theoretical justification of the split hazard approach in the methodology section, and based on the other diagnostics, we believe that the split-hazard model is theoretically the best way to model individual adoption timing. (see also Kamakura, Kossar, and Wedel 2004). Moreover, according to the STATA program it is rather difficult for the more complex split-hazard model to deliver a better fit. Still, two out of our three fit measures favor the split-hazard. Hence, in the following we will discuss the results of the split-hazard model only. The ordinary hazard model does not lead to different conclusions with respect to the variables of interest ${ }^{\mathrm{iv}}$.

In Table 2, we summarize the results of the split-hazard model. In the logit part of our model, positive coefficients indicate a positive effect on the probability of eventual adoption, whereas in the hazard part, positive coefficients indicate a positive effect on the hazard rate. Consequently, variables with positive coefficients shorten the time to adoption. The estimation results reveal some significant effects of our included relationship characteristics in the logit-part of the model, indicating that the non-adopters (or customers resisting the innovation) are indeed different from adopters. The results also reveal significant effects of the considered marketing communications. We will now discuss our results more specifically.

$<$ Table 2 about here $>$

\section{Marketing Communications}

Direct marketing communications have a significant positive effect on the hazard rate; these effects substantially shorten consumers' time to adoption. We also find a positive effect for service and brand advertising on adoption timing. When we test for the equality of the coefficients of service and brand advertising, we find that the effect of service advertising is significantly greater than that of brand advertising $(p<.01)$. Therefore, $\mathrm{H}_{1}, \mathrm{H}_{2}, \mathrm{H}_{3}$, and $\mathrm{H}_{4}$ are 
all supported. In addition, our hypothesis regarding the market-making effect of competitive service advertising $\left(\mathrm{H}_{5}\right)$ is confirmed; we find a positive significant effect on adoption timing. Finally, brand advertising by competitors has a significant negative effect, which implies that it lengthens the time to adoption, as we hypothesized in $\mathrm{H}_{6}$. Overall, the lagged effects of advertising expenditures are not significant, except for that of brand advertising ${ }^{\mathrm{v}}$. The size of all mass advertising effects is considerably smaller than the size of the DMC effects; i.e. no increase in advertising expenditures can equal the effect of a DMC offer on individual hazard rates. However, the stronger DMC effect may be context dependent, as we will discuss in our discussion and limitations section.

\section{Covariates}

Relationship age has a significant (nonlinear) effect on adoption probability. Specifically, the probability of eventual adoption increases as the age of the customer's relationship with the provider increases, up to approximately three years. For customers that have been with the provider for more than three years, the adoption probability decreases. This finding is to some extent in line with Reinartz and Kumar (2003), who report a nonlinear relationship between interpurchase times and lifetime duration. We do not find a significant effect of relationship age on adoption timing.

Service usage appears to be a significant indicator of both adoption probability and adoption timing. Customers with high usage levels are less likely to adopt the new service eventually than are customers with low usage levels. This effect might occur, because customers with high usage levels are very satisfied with the services they currently receive. Hence, they see no need for adopting a new developed service. Given that they adopt, customers with high usage levels turn out to be the fastest adopters. This positive relationship between service usage and adoption timing suggests that, despite a low adoption probability, heavy users tend to adopt faster than lighter users.

\section{Interaction Effects}

In addition to our analyses of the main effects displayed in Table 2, we also perform an analysis on any possible interaction effects between DMC and MMC, as well as between marketing communications and relationship characteristics. We include all interaction terms simultaneously in the split-hazard model we used previously, which does not change the other coefficients significantly. Therefore, we report only the interaction effects and relevant main effects in Table 3. Adding the interaction effects to the model improves the total model fit 
significantly $\left(\chi^{2}(7)=24.724 ; p<0.001\right)$; the AIC statistic also decreases from 27,229.89 to $27,219.17$.

\section{$<$ Table 3 about here $>$}

The first interaction effect we investigate is between DMC and service and brand advertising. The results suggest a negative interaction effect between DMC and service advertising, which indicates that the combined effect of the two types of marketing efforts on adoption timing is less than the sum of the separate positive effects. The interaction effect between DMC and brand advertising is not significant. Therefore, we do not find evidence for communication synergies between DMC and brand advertising, as we hypothesized in $\mathrm{H}_{7}$ and $\mathrm{H}_{8}$.

The second interaction effect we examine is that between relationship age and all types of marketing communications. The results suggest that the influence of service advertising efforts - whether by the provider or its competitors - is greater for customers that have been with the provider for a longer time. We cannot find any significant interaction effects between (competitive) brand advertising and relationship age or between DMC and relationship age.

\section{Discussion and Implications}

In this study, we investigate the effects of marketing communications on the individual adoption timing of a new e-service by existing customers of a large Dutch telecom provider. In doing so, we integrate the literature streams of new product adoption and customer management. This integration and our data-including customer adoption behavior, customer-specific marketing interventions, advertising expenditure data, customer relationship characteristics, and customer characteristics-enable us to contribute to both literature streams. We report a summary of our hypothesis testing results in Table 4, and we discuss our most important findings and contributions next.

$<$ Table 4 about here $>$

First, we study both direct marketing communications and mass communications. These mass communications include both advertisings communicating the new e-service and brand advertisings, while we also consider the impact of these two advertising types from competing suppliers. In support of prior customer management research findings, we find that DMC shortens adoption timing (e.g. Verhoef, Franses, and Hoekstra 2001). This is an important extension of our knowledge on the possible effects of DMC. It not only influences 
for example cross-buying of existing services, it also impacts the purchase of newly introduced services. The finding of an effect of DMC is also important for the adoption literature, as so far adoption researchers have ignored the impact of DMC on individual adoption behavior. Our study results clearly emphasize the importance of DMC in influencing the adoption behavior of existing customers. Consistent with previous adoption studies and diffusion research, we find a positive effect of mass advertising expenditures of the focal supplier on the adoption speed of individual customers. The effect on adoption timing is, however, remarkably smaller than the effect of DMC. This could point to the fact that, in this particular setting, mass communication, due to its focus on creating awareness and information provision, does not influence adoption behavior very strongly. In order to really affect behavior, more action-oriented communications, such as DMC, are required. However, this stronger effect of DMC may also be explained by the fact that we study adoption behavior of existing customers, who might be more responsive to individually targeted marketing efforts. Furthermore, this result may be context dependent, since we could only investigate one type of DMC, and did not have any influence on the content of the message. For example, it might have been possible for the provider to adjust the message to the individual customer's situation. Moreover, the strong effect of DMC might also be due to the firm doing a good job of selecting customers who to contact by phone. Note, however, that we controlled for this by including several covariates. Overall, we cannot draw any generalizable conclusions from the relatively strong DMC effect compared to the effect of MMC. Future research might aim to replicate our findings.

Second, this is the first study explicitly distinguishing between brand advertising and service advertising. We show that the effects of each type of mass advertising on individual adoption timing are notably different. Mass advertising specifically related to the new service has a greater effect on the time to adoption than does general mass advertising for the service provider's brand. This is of course not an unexpected finding, as service advertising has a more specific focus on the new service. Through service advertising, service providers mainly build consumer awareness and interest with respect to the new service category. However, the positive effect of general brand advertising on adoption behavior is remarkable. Based on general advertising theories, we argued that brand advertising positively impacts the attitude towards the brand, which then positively affects adoption behavior. There is, however, still much unknown about this effect. For example, do improved brand perceptions indeed positively affect adoption behavior? In this study, we did not account for intervening brand attitudes (nor service attitudes). It would be very interesting to include these attitudes in more 
extended models in future research. As noted, mass advertising has been ignored by customer management research for several reasons. Our study indeed shows that mass communication affects adoption behavior of existing customers. This is an important finding, although it might be due to the specific nature of the behavior: existing customers also need to be informed about the new service, providing a more important role for mass advertising. However, it may also point to a too narrow view of customer management researchers, who assume that after acquisition, existing customers mainly focus on the relationship itself and are no longer affected by mass advertising efforts. The important role of advertising is generally acknowledged in frequently consumed packaged goods, where advertising elasticity's are found between 0 and 0.2 percent (Assmus, Farley, and Lehmann 1984; Vakratas and Ambler 1999). In these markets, advertising is required to continuously reinforce the brand position in the consumers' mind in order to affect buying behavior and thus brand loyalty in the store. The question is whether advertising also affects customer behaviors, such as customer retention or cross-buying, of existing customers in more longterm (contractual) relationships. Our study may indeed point to the existence of these effects. However, future research should empirically establish whether these effects are actually present.

Third, our results show that competitive advertising efforts featuring similar services can accelerate the adoption process for first movers as well, which suggests that through service advertising, service providers mainly build consumer awareness and interest with respect to the new service category. It also confirms the market-making effect, which has been shown to be relevant at the aggregate diffusion level (e.g. Krishnan, Bass, and Kumar 2000). Our study is the first to show this effect at the individual adoption level. Our results also show that competitive brand advertising lengthens adoption timing. This finding is rather interesting, as it shows that even the adoption of new services by existing customers is affected by competitive actions not related to the specific new service. Theoretically, we reasoned that this effect might exist, because of the effects of competitive advertising on brand attitudes of both the focal supplier and the competitor. We do, however, have no empirical evidence for this link, as we do not observe brand attitudes. Clearly, more research is required here. The inclusion of competitive mass communication efforts is totally new for the customer management research literature. Most researchers have ignored the impact of competitive actions, although they are acknowledged to be relevant (e.g. Keiningham, Purkins-Munn, and Evans 2003). Our results emphasize the importance of these competitive 
actions. A next step in customer management research would be that researchers would include more competitive variables in their models.

Fourth, we examined various possible interaction effects in our analysis. Although we expected a positive synergy between DM and mass marketing efforts, we find some rather less straightforward effects, including an unexpected negative interaction between service advertising and DMC. Past research have also identified some negative interaction effects. Naik, Raman and Winer (2005) argue that the price oriented nature of promotions may reduce the effectiveness of advertising in building brands. On the other hand advertising may lower the consumer sensitivity to promotions. Narayanan, Desiraju and Chintagunta (2004) report a negative interaction effect between detailing and advertising in pharmaceutical markets. The reasoning of Bass et al. (2006) is that there might be a kind of overkill. The advertising combined with DMC may result in too much attention for the new service, resulting in a negative interaction effect. Overall, there is clearly more research required in understanding these negative interaction effects, which are found more commonly in empirical research. We cannot find any significant interactions between brand advertising and DMC, which implies that there is no synergy between these marketing variables.

The interaction effects between marketing efforts and relationship age provide some more intuitive results. Service advertising has a greater impact on more loyal customers, and the positive interaction effect between competitive service advertising and relationship age implies that the market-making effect does not work well for relatively new customers. Overall, the interaction effects between relationship age and marketing efforts provide further evidence that customers' heterogeneous responses to marketing efforts may be explained, at least partially, by relationship characteristics such as relationship age (Rust and Verhoef 2005).

Fifth, from a modeling perspective, our research clearly shows that one should account for the fact that a certain part of the customers will probably never adopt the new service. This supports the theoretical notion of innovation resistance mentioned in de adoption literature. So far, most adoption researchers do not account for this in their econometric model (e.g. Steenkamp and Gielens 2003). Hence, our study is one of the few studies using a split-hazard model accounting for this effect at the individual adoption level. We should, however, mention that our model might also work well, because of the limited time frame of the data. Usually, the take-off of a new product of service may take several years (Tellis, Stremersch, and Yin 2003). Hence, we do not observe adoption for a large part of the existing customers included in our study, which might now be considered as non-adopters in our model, but in 
fact will adopt the product several years from now. However, recent adoption figures about the studied new service still show a limited number of adopters (see also Figure 2), indicating that innovation resistance might indeed be a problem. Notably, the split hazard model may also have other applications in customer management research. For example, when modeling relationship duration one might assume that there is a group of customers very unlikely to churn due to for example high switching costs, while there is another group of customers who is clearly at risk for churning. The latter group might be very receptive to service improvement efforts, while the first group is almost non-responsive. So far, researchers have not acknowledged modeling relationship duration accounting for the appearance of these two groups of customers (e.g. Bolton 1998).

Sixth, our study is the first to investigate customer adoption of new services using customer database data. These data offer some interesting insights, especially with respect to the effects of behavioral relationship characteristics on customer adoption behavior. Customers who have been with the provider for two or three years have the highest probability to adopt the new e-service eventually. The lower adoption probability for new customers may be explained by the contractual setting; these customers are still locked in to their recently established contract with the provider, and upgrading to a contract that includes the new service would be costly. The low adoption probability of customers who have been with the provider for a very long time could be explained by customer lifecycle effects, such that in the later stages of the customer lifecycle, customers are not likely to adopt new products or services. Customers with high usage levels, who are assumed to have a deeper relationship with the provider, are less likely to adopt the new service, which seems counterintuitive. However, customers with high usage levels who do adopt indicate a relatively short time to adoption. Furthermore, we find that domain-specific innovativeness does not affect the probability of eventual adoption but does shorten the time to adoption. One cautious note is required, as our measure for domain specific innovativeness might be imperfect. Future research might for example use perceptual innovativeness measures instead of our used behavioral indicator.

\section{Management Implications}

Speeding up the adoption of newly introduced services is very important to many firms. This especially holds in the telecom industry, where services are linked to large network technology investments. A successful introduction of these new services is required in order 
to get return on these investments. Existing customers are an important target group in the introduction of new services. The question is, however, which marketing communications the firm should use to speed up adoption. Our results indicate that firms can both use DMC and MMC to shorten adoption timing. However, the effect of DMC is much larger than the effect of MMC. Hence, our results seem to suggest that speeding up adoption timing among existing customers should mainly be done with DMC. The role of MMC is only limited. MMC may, however, still be required to reach non-customers as well. On the other hand, one strategy might be to focus on existing customers first, in order to create a sufficiently large customer base to further spread the new technology into the market. This might point to potential costsavings for firms, if they first use relatively cheap and more effective DMC, and after that use the existing customer base to create network effects.

Our results also show the importance of competitive advertising effects on the new service. A useful strategy therefore might involve two or more competitors that simultaneously introduce a new service; this approach should accelerate the adoption process for every player in the market.

The results of our study, particularly the exploratory analyses of the interaction effects between marketing efforts and relationship age, reveal that customer loyalty plays a significant role in the adoption process of existing customers. We find that loyal customers adopt sooner than relatively new customers and have a better response to mass marketing efforts. Therefore, building customer loyalty is not only important for customer retention and cross-selling but also for the adoption of new and additional services.

\section{Research Limitations and Further Research}

Our study has several limitations that suggest possible directions for further research. First, we only consider one service introduction in the telecom industry for a specific company. The question is whether our findings are generalizable to other contexts as well. Of course, this specific industry, company, and service have specific characteristics (i.e. a high degree of technological turbulence, high involvement, one of the larger market players, etc.). For example, one can imagine that in markets with lower involvement products, the effects of mass advertising will be smaller. Clearly, more research is required to study the effect of marketing communications on adoption behavior. Studying other industries and services will allow us to study which market- and service characteristics moderate the effects of marketing communications. 
Another important limitation is our consideration of the adoption behavior of existing customers only. Accordingly, our findings apply to this group alone. However, a considerable number of adopters had not been customers of the provider before they adopted the new service. These customer acquisitions as a result of the introduction of the new service were not observed by the provider prior to the adoption, so we do not take them into account. It would be interesting to investigate the specific effects of marketing communications on the adoption behavior of this specific group of consumers.

Furthermore, we do not have any data about prices, income levels, or customer attitudes. Prices will most likely have a considerable impact on the adoption timing of customers, but such data typically are difficult to retrieve in a mobile service context. Including customer attitudes in the model, such as customer satisfaction and the perceived usefulness of the new service, also would be an interesting extension that could provide new and valuable insights into individual adoption behavior (e.g. Meuter et al. 2005).

Our results are also limited to the used communication types and content used by this provider. For example, the DMC efforts consisted of phone calls from the provider to existing customers. The found effects might be different if other instruments or content would be used. Therefore, we cannot generalize our findings on the relative size of the effects of DMC and MMC on adoption timing. Future research might consider how instruments and content moderate the effect of marketing communications on adoption behavior.

Finally, we defined individual adoption as a dichotomous event, that is, the first trial of a new service. Continuous usage of the new service may be a better characterization of the adoption decision, because some adopters could cease to use the service after the first trial. Therefore, a promising direction for further research would be to investigate postadoption usage and disadoption of new services in a customer management context. 
Table 1:

Measurements and Descriptives of Explanatory Variables

\begin{tabular}{|c|c|c|c|}
\hline Variable & Label & Average & $\begin{array}{c}\text { Standard } \\
\text { Deviation }\end{array}$ \\
\hline \multicolumn{4}{|l|}{ Marketing Communication } \\
\hline DMC & & & \\
\hline Dummy for individual offer by telephone for customer $\mathrm{i}$ in month $\mathrm{t}$ & $D M C_{i t}$ & .09 & .13 \\
\hline $\begin{array}{l}\text { MMC } \\
\text { Service advertising }\end{array}$ & & & \\
\hline $\begin{array}{l}\text { Advertising expenditures in millions of euros in month } \mathrm{t} \text { with } \\
\text { respect to the new service } \\
\text { Brand advertising }\end{array}$ & $S A_{t}$ & 1.11 & .88 \\
\hline $\begin{array}{l}\text { Advertising expenditures in millions of euros in month } \mathrm{t} \text {, not related } \\
\text { to the new service } \\
\text { CMMC } \\
\text { Competitive service advertising }\end{array}$ & $B A_{t}$ & 1.50 & 1.05 \\
\hline $\begin{array}{l}\text { Advertising expenditures of all competitors in millions of euros in } \\
\text { month } \mathrm{t} \text {, related to a similar service } \\
\text { Competitive brand advertising }\end{array}$ & $C S A_{t}$ & .95 & 1.12 \\
\hline $\begin{array}{l}\text { Advertising expenditures of all competitors in millions of euros in } \\
\text { month } t \text {, not related to a similar service }\end{array}$ & $C B A_{t}$ & 6.23 & 2.44 \\
\hline \multicolumn{4}{|l|}{ Relationship Characteristics } \\
\hline $\begin{array}{l}\text { Relationship Age } \\
\text { Number of years customer } \mathrm{i} \text { has been with the provider at } \mathrm{t}=1\end{array}$ & $R A_{i}$ & 2.67 & 1.65 \\
\hline $\begin{array}{l}\text { Service Usage } \\
\text { Average monthly amount spent by customer i before } \mathrm{t}=1\end{array}$ & $S U_{i}$ & 3.39 & 4.03 \\
\hline \multicolumn{4}{|l|}{ Customer Characteristics } \\
\hline $\begin{array}{l}\text { Gender } \\
(\text { male }=0 ; \text { female }=1)\end{array}$ & Gend $_{i}$ & .26 & .43 \\
\hline $\begin{array}{l}\text { Age } \\
\text { At } \mathrm{t}=1\end{array}$ & $\mathrm{Age}_{i}$ & 37.93 & 10.45 \\
\hline $\begin{array}{l}\text { Domain-specific innovativeness } \\
\text { Dummy for usage of prior generation e-service by customer i }\end{array}$ & Innov $_{i}$ & .03 & .18 \\
\hline
\end{tabular}


Table 2:

Estimation Results

\begin{tabular}{|c|c|c|c|c|c|c|}
\hline & \multicolumn{3}{|c|}{$\begin{array}{l}\text { Logit Part: } \\
\text { P(Adoption) }\end{array}$} & \multicolumn{3}{|c|}{$\begin{array}{c}\text { Hazard Part: } \\
\text { Time to Adoption }\end{array}$} \\
\hline & Coeff. & z-Value & & Coeff. & z-Value & \\
\hline $\mathrm{t}$ & NA & & & .1618 & 11.49 & $* * *$ \\
\hline$t^{2}$ & NA & & & -.0048 & -9.82 & $* * *$ \\
\hline $\mathrm{DMC}$ & NA & & & 1.8652 & 43.20 & $* * *$ \\
\hline Service advertising & NA & & & .2243 & 7.22 & $* * *$ \\
\hline Service advertising $(t-1)$ & NA & & & .0012 & .05 & \\
\hline Brand advertising & NA & & & .0521 & 2.25 & $* *$ \\
\hline Brand advertising $(\mathrm{t}-1)$ & NA & & & .0432 & 1.88 & $*$ \\
\hline Comp. service advertising & NA & & & .0969 & 4.85 & $* * *$ \\
\hline Comp. service advertising $(\mathrm{t}-1)$ & NA & & & -.0065 & -.29 & \\
\hline Comp. brand advertising & NA & & & -.0863 & -10.26 & $* * *$ \\
\hline Comp. brand advertising $(\mathrm{t}-1)$ & NA & & & -.0078 & -.85 & \\
\hline Relationship age & .8493 & 1.75 & $*$ & .0521 & 1.00 & \\
\hline Relationship age $^{2}$ & -.1296 & -1.86 & $*$ & -.0033 & -.42 & \\
\hline Service usage & -.2164 & -3.00 & $* * *$ & .0580 & 4.45 & $* * *$ \\
\hline Service usage $^{2}$ & .0032 & 2.35 & $* *$ & -.0009 & -2.45 & $* *$ \\
\hline Age & -1.6270 & -.88 & & -.2123 & -1.55 & \\
\hline $\mathrm{Age}^{2}$ & .2413 & .97 & & -.0075 & -.46 & \\
\hline Gender & .4401 & .62 & & -.1486 & -2.44 & $* *$ \\
\hline Domain-specific innovativeness & -.2685 & -.44 & & .3166 & 2.84 & $* * *$ \\
\hline Constant & 5.5730 & 1.67 & $*$ & -3.6189 & -11.98 & $* * *$ \\
\hline Log-likelihood & \multicolumn{3}{|c|}{$-13,586.947$} & & & \\
\hline Likelihood ratio test & \multicolumn{3}{|c|}{$\chi^{2}(28)=1935.99 * * *$} & & & \\
\hline AIC-statistic & \multicolumn{3}{|l|}{$27,229.89$} & & & \\
\hline BIC-statistic & \multicolumn{3}{|l|}{$27,401.83$} & & & \\
\hline
\end{tabular}


Table 3:

Estimation Results Interaction Effects

\begin{tabular}{|c|c|c|c|}
\hline \multirow[b]{3}{*}{$\mathrm{DMC}$} & \multicolumn{3}{|c|}{$\begin{array}{c}\text { Hazard Part: } \\
\text { Time to Adoption }\end{array}$} \\
\hline & Coeff. & z-Value & \\
\hline & 1.9558 & 16.44 & $* * *$ \\
\hline Service advertising (SA) & .1841 & 4.88 & $* * *$ \\
\hline Brand advertising (BA) & .0323 & 1.06 & \\
\hline Competitive service advertising (CSA) & .0829 & 3.48 & $* * *$ \\
\hline Competitive brand advertising (CBA) & -.0819 & -8.01 & $* * *$ \\
\hline Relationship age (RA) & -.0345 & -.41 & \\
\hline $\mathrm{RA}^{2}$ & .0038 & .36 & \\
\hline $\mathrm{DMC} \times \mathrm{SA}$ & -.1226 & -1.97 & $* *$ \\
\hline $\mathrm{DMC} \times \mathrm{BA}$ & .0424 & .92 & \\
\hline $\mathrm{RA} \times \mathrm{DM}$ & -.0202 & -.43 & \\
\hline $\mathrm{RA} \times \mathrm{SA}$ & .0742 & 2.89 & $* * *$ \\
\hline $\mathrm{RA} \times \mathrm{BA}$ & .0004 & 0.02 & \\
\hline $\mathrm{RA} \times \mathrm{CSA}$ & .0380 & 2.12 & $* *$ \\
\hline $\mathrm{RA} \times \mathrm{CBA}$ & -.0059 & -.71 & \\
\hline Log-likelihood & $-13,574.58$ & & \\
\hline Likelihood-ratio test & $\chi^{2}(35)=$ & 1960.71 & \\
\hline AIC-statistic & $27,219.17$ & & \\
\hline BIC-statistic & $27,434.09$ & & \\
\hline
\end{tabular}


Table 4:

Summary of Hypothesis Testing Results

\begin{tabular}{llccc}
\hline \multicolumn{1}{c}{ Variable } & Hypothesis & $\begin{array}{c}\text { Hypothesized Effect } \\
\text { on Adoption Timing }\end{array}$ & Finding & Conclusion \\
\hline DMC & $\mathrm{H}_{1}$ & + & + & Supported \\
Service advertising & $\mathrm{H}_{2}, \mathrm{H}_{4}$ & + & + & Supported \\
Brand advertising & $\mathrm{H}_{3}, \mathrm{H}_{4}$ & + & + & Supported \\
Competitive service advertising & $\mathrm{H}_{5}$ & + & + & Supported \\
Competitive brand advertising & $\mathrm{H}_{6}$ & - & - & Supported \\
DMC $\times$ Service advertising & $\mathrm{H}_{7}$ & + & - & Not supported \\
DMC $\times$ Brand advertising & $\mathrm{H}_{8}$ & + & n.s. & Not supported \\
\hline
\end{tabular}

${ }^{\text {a }}$ Positive effects indicate a shorter time to adoption 
Figure 1:

Conceptual Framework

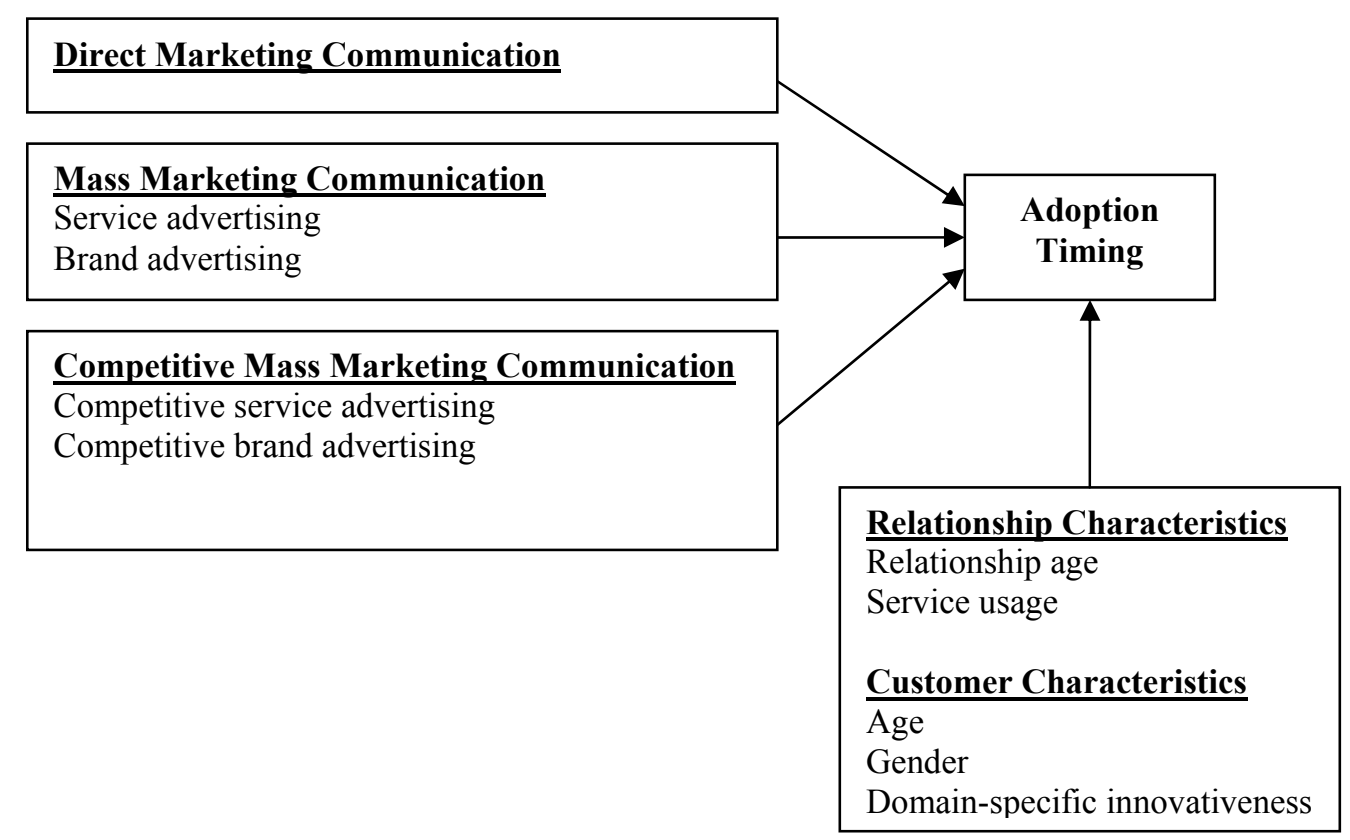


Figure 2:

Monthly Adoptions in Sample

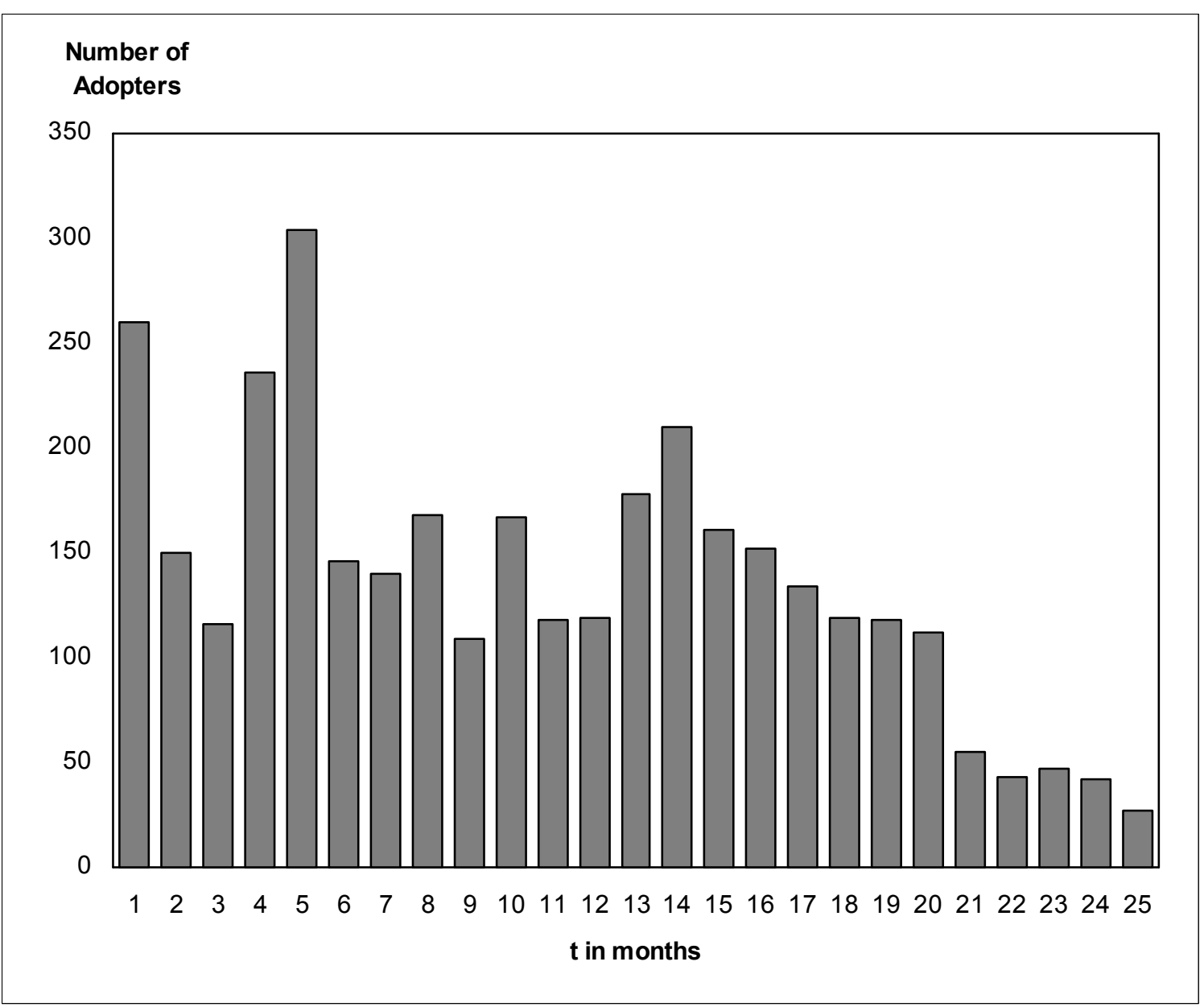




\section{References}

Allison, Paul D. (1982), "Discrete-Time Methods for the Analysis of Event Histories," in Sociological Methodology, S. Leinhardt, ed. San Francisco: Jossey-Bass, 61-98.

Ambler, Tim, C.B. Bhattacharya, Julie Edell, Kevin Lane Keller, Katherine N. Lemon, and Vikas Mittal (2002), "Relating Brand and Customer Perspectives on Marketing Management," Journal of Service Research, 5 (August), 13-25.

Arts, Joep W.C., Ruud T. Frambach, and Tammo H. A. Bijmolt (2005), “What Really Drives Innovation Adoption? A Meta-Analysis on the Antecedents of Intentional Versus Actual Consumer Adoption Behavior,” working paper, Department of Marketing, Free University Amsterdam.

Assmus, Gert, John U. Farley, and Donald R. Lehmann (1984), "How Advertising Affects Sales: Meta-Analysis of Econometric Results," Journal of Marketing Research, 21 (February), 65-74.

Bagozzi, Rick P. and Kyu-Hyun Lee (1999), “Consumer Resistance to and Acceptance of Innovations," in Advances in Consumer Research, Vol. 26, E.J. Arnould and L. Scott, Provo, UT: Association for Consumer Research, 218-25.

Bass, Frank M., Norris Bruce, Summit Majumdar, and B.P.S. Murthi (2005), “A Dynamic Bayesian Model of Advertising Copy Effectiveness in the Telecommunications Sector," working paper, School of Management, University of Texas at Dallas.

— Trichy V. Krishnan, and Dipak C. Jain (1994), "Why the Bass Model Fits Without Decision Variables," Marketing Science, 13 (3), 203-223.

Bolton, Ruth N. (1998), “A Dynamic Model of the Duration of the Customer's Relationship with a Continuous Service Provider: The Role of Satisfaction," Marketing Science, 17 (1), 45-65. 
and Katherine N. Lemon (1999), “A Dynamic Model of Customers’ Usage of Services: Usage as an Antecedent and Consequence of Satisfaction," Journal of Marketing Research, 36 (May), 171-86.

and Peter C. Verhoef (2004), “The Theoretical Underpinnings of Customer Asset Management: A Framework and Propositions for Future Research," Journal of the Academy of Marketing Science, 32 (Summer), 1-20.

Boulding, William, Richard Staelin, Michael Ehret, and Wesley J. Johnston (2005), “A Customer Relationship Management Roadmap: What Is Known, Potential Pitfalls, and Where to Go," Journal of Marketing, 69 (October), 155-66.

Chandrashekaran, Murali and Rajiv K. Sinha (1995), "Isolating the Determinants of Innovativeness: A Split-Population Tobit (Spot) Duration Model of Timing and Volume of First and Repeat Purchase," Journal of Marketing Research, 32 (November), 444-56.

Citrin, Alka Varma, David E. Sprott, Steven N. Silverman, and Donald E. Stem (2000), “Adoption of Internet Shopping: The Role of Consumer Innovativeness," Industrial Data and Management Systems, 100 (7), 294-300.

Dekimpe, Marnik G., Linda M. Van de Gucht, Dominique M. Hanssens, and Keiko I. Powers (1998), "Long-Run Abstinence After Narcotics Abuse: What Are the Odds?" Management Science, 44 (11), 1478-92.

Donkers, Bas, Philip Hans Franses, and Peter C. Verhoef (2003), "Selective Sampling for Binary Choice Models," Journal of Marketing Research, 40 (November), 492-97.

Dwyer, F. Robert, Paul H. Schurr, and Sejo Oh (1987), "Developing Buyer-Seller Relationships," Journal of Marketing, 51 (April), 11-27.

The Economist (2004), "Vision, Meet Reality: Mobile 3G Telecoms," 372 (8391), 63-65.

Franses, Philip Hans (2005), "Diagnostics, Expectations, and Endogeneity," Journal of Marketing Research, 42 (February), 27-29. 
Gatignon, Hubert and Thomas S. Robertson (1991), "Innovative Decision Processes," in Handbook of Consumer Behavior, Harold H. Kassarjian and Thomas S. Robertson, eds. Englewood Cliffs, NJ: Prentice Hall College Division, 316-48.

Golder, Peter N. and Gerard J. Tellis (1997), "Will It Ever Fly? Modeling the Takeoff of Really New Consumer Durables," Marketing Science, 16 (3), 256-70.

Goldsmith, Ronald E., Jon B. Freiden, and Jacqueline K. Eastman (1995), “The Generality/Specificity Issue in Consumer Innovativeness Research,” Technovation, 15 (10), 601-612.

Gupta, Sunil, Donald R. Lehmann, and Jennifer Ames Stuart (2004), "Valuing Customers," Journal of Marketing Research, 41 (February), 7-18.

Hitt, Lorin M. and Frances X. Frei (2002), "Do Better Customers Utilize Electronic Distribution Channels? The Case of PC Banking," Management Science, 48 (6), 732 48.

Hogan, John E., Donald R. Lehmann, Maria Merino, Rajendra K. Srivastava, Jacqueline S. Thomas, and Peter C. Verhoef (2002), "Linking Customer Assets to Financial Performance," Journal of Service Research, 5 (August), 26-38.

, Katherine N. Lemon, and Barak Libai (2003), "What Is the True Value of a Lost Customer?" Journal of Service Research, 5 (February), 196-208.

Horsky, Dan and Leonard S. Simon (1983), "Advertising and the Diffusion of New Products," Marketing Science, 2 (1), 1-17.

Im, Subin, Barry L. Bayus, and Charlotte H. Mason (2003), “An Empirical Study of Innate Consumer Innovativeness, Personal Characteristics, and New-Product Adoption Behavior," Journal of the Academy of Marketing Science, 31 (Winter), 61-73.

Kalish, Shlomo (1985), “A New Product Adoption Model with Price, Advertising, and Uncertainty," Management Science, 31 (12), 1569-85. 
Kamakura, Wagner A., Bruce S. Kossar, and Michel Wedel (2004), "Identifying Innovators for the Cross-Selling of New Products," Management Science, 50 (8), 1120-33.

Keiningham, Timothy L., Tiffany Purkins-Munn, and Heather Evans (2003), “The Impact of Customer Satisfaction on Share-of-Wallet in a Business-to-Business Environment," Journal of Service Research, 6 (August), 37-50.

Krishnamurthy, Sandeep (2000), “Enlarging the Pie Vs. Increasing One's Slice: An Analysis of the Relationship Between Generic and Brand Advertising," Marketing Letters, 11 (February), 37-48.

Krishnan, Trichy V., Frank M. Bass, and V. Kumar (2000), "Impact of a Late Entrant on the Diffusion of a New Product/Service,” Journal of Marketing Research, 37 (May), 26978.

Lodish, Leonard M., Magid M. Abraham, Jeanne Livelsberger, Beth Lubetkin, Bruce Richardson, and Mary Ellen Stevens (1995), “A Summary of Fifty-Five In-Market Experimental Estimates of the Long-Term Effect of TV-Advertising," Marketing Science, 14 (3), G133-40.

Mahajan, Vijay and Eitan Muller (1996), "Timing, Diffusion, and Substitution of Successive Generations of Technological Innovations: The IBM Mainframe Case," Technological Forecasting and Social Change, 51 (2), 109-132.

— Subhash Sharma, and Robert D. Buzzel (1993), “Assessing the Impact of Competitive Entry on Market Expansion and Incumbent Sales," Journal of Marketing, 57 (July), 39-52.

Manning, Kenneth C., William O. Bearden, and Thomas J. Madden (1995), "Consumer Innovativeness and the Adoption Process," Journal of Consumer Psychology, 4 (4), 329-45. 
Meuter, Matthew L., Mary Jo Bitner, Amy L. Ostrum, and Stephen W. Brown (2005), "Choosing Among Alternative Service Delivery Modes: An Investigation of Customer Trial of Self-Service Technologies," Journal of Marketing, 69 (April), 61-83.

Midgley, David F. and Grahame R. Dowling (1993), “A Longitudinal Study of Product Form Innovation: The Interaction Between Predispositions and Social Messages," Journal of Consumer Research, 19 (March), 611-25.

Mittelstaedt, Robert A., Sanford L. Grossbart, William W. Curtis, and Stephen P. Devere (1976), “Optimal Simulation Level and Adoption Decision Process,” Journal of Consumer Research, 3 (September), 84-94.

Naik, Prasad A. and Kalyan Raman (2003), "Understanding the Impact of Synergy in Multimedia Communications," Journal of Marketing Research, 40 (November), 37588.

Narayanan, Sridhar, Ramarao Desiraju, and Pradeep K. Chintagunta (2004), "Return on Investment Implications for Pharmaceutical Promotional Expenditures: The Role of Marketing-Mix Interactions,” Journal of Marketing, 68 (October), 90-105.

Nerlove, Marc and Kenneth J. Arrow (1962), “Optimal Advertising Policy Under Dynamic Conditions," Economica, 29 (114), 129-42.

Pae, Jae H. and Donald R. Lehmann (2003), "Multigeneration Innovation Diffusion: The Impact of Intergeneration Time," Journal of the Academy of Marketing Science, 31 (Winter), 36-45.

Ram, S. and Jagdish N. Sheth (1989), "Consumer Resitance to Innovations: The Marketing Problem and Its Solutions," Journal of Consumer Marketing, 6 (2), 5-14. 
Reinartz, Werner J. and V. Kumar (2003), “The Impact of Customer Relationship Characteristics on Profitable Lifetime Duration," Journal of Marketing, 67 (January), 77-99.

Rogers, Everett M. (1995), Diffusion of Innovations, 4th ed. New York: The Free Press.

Rossiter, John R. and Larry Percy (1997), Advertising Communications \& Promotion Management. Boston: Irwin/McGraw-Hill.

Rust, Roland T. and Peter C. Verhoef (2005), "Optimizing the Marketing Interventions Mix in Intermediate-Term CRM," Marketing Science, 24 (3), 477-89.

—, Valarie A. Zeithaml, and Katherine N. Lemon (2000), Driving Customer Equity. New York: The Free Press.

Schmidt, Peter and Ann Dryden Witte (1989), "Predicting Criminal Recidivism Using 'Split Population’ Survival Time Models,” Journal of Econometrics, 40 (January), 141-59.

Schultz, Don E., Stanley I. Tannenbaum, and Robert F. Lauterborn (1993), Integrated Marketing Communications. Lincolnwood, IL: NTC Business Books.

Sheth, Jagdish N. (1981), "Psychology of Innovation Resistance: The Less Developed Concept in Diffusion Research," Research in Marketing, 4 (3), 273-82.

Shugan, Steven M. (2004), “Endogeneity in Marketing Decision Models,” Marketing Science, $23(1), 1-3$.

Simon, Hermann and Karl-Heinz Sebastian (1987), "Diffusion and Advertising: the German Telephone Campaign,” Management Science, 33 (4), 451-66.

Sinha, Rajiv K. and Murali Chandrashekaran (1992), “A Split Hazard Model for Analyzing the Diffusion of Innovations,” Journal of Marketing Research, 29 (February), 116-27. 
Steenkamp, Jan-Benedict E.M. and Steven M. Burgess (2002), “Optimum Simulation Level and Exploratory Consumer Behavior in an Emerging Consumer Market," International Journal of Research in Marketing, 19 (June), 131-50.

and Katrijn Gielens (2003), "Consumer and Market Drivers of the Trial Probability of New Consumer Packaged Goods," Journal of Consumer Research, 30 (December), $368-84$.

, Frenkel Ter Hofstede, and Michel Wedel (1999), “A Cross-National Investigation into the Individual and National Cultural Antecedents of Consumer," Journal of Marketing, 63 (April), 55-69.

Szmigin, Isabelle and Gordon Foxall (1998), “Three Forms of Innovation Resistance: The Case of Retail Payment Methods," Technovation, 18 (6-7), 459-68.

Tellis, Gerard J., Stefan Stremersch, and Eden Yin (2003), “The International Takeoff of New Products: The Role of Economics, Culture, and Country Innovativeness," Marketing Science, 22 (2), 188-208.

Vakratas, Demetrios and Tim Ambler (1999), "How Advertising Works: What Do We Really Know?” Journal of Marketing, 63 (January), 26-43.

Van Damme, Eric (2002), “The European UMTS-Auctions,” European Economic Review, 46 (4-5), 846-58.

Van den Bulte, Christophe and Gary L. Lilien (2001), "Two-Stage Partial Observability Models of Innovation Adoption," working paper, Wharton School, University of Pennsylvania.

Venkatesan, Rajkumar and V. Kumar (2004), “A Customer Lifetime Value Framework for Customer Selection and Resource Allocation Strategy," Journal of Marketing, 68 (October), 106-125. 
Verhoef, Peter C. (2003), "Understanding the Effect of Customer Relationship Management Efforts on Customer Retention and Customer Share Development," Journal of Marketing, 67 (October), 30-45.

_ _ Philip Hans Franses, and Janny Hoekstra (2001), “The Impact of Satisfaction and Payment Equity on Cross-Buying: A Dynamic Model for a Multi-Service Provider,” Journal of Retailing, 77 (Fall), 359-78.

— $—$, and (2002), "The Effect of Relational Constructs on Customer Referrals and Number of Services Purchased From a Multiservice Provider: Does Age of Relationship Matter?” Journal of the Academy of Marketing Science, 30 (Summer), $202-216$. 


\title{
Endnotes
}

\begin{abstract}
${ }^{i}$ In this study we will mainly use the term service when discussing adoption, given our empirical focus on new service adoption. However, the theoretical discussion both holds for services and products.

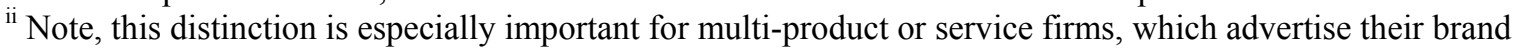
(and a portfolio of offered products or services) and their newly introduced service to both potential and current customers.

iii Switchers to the competitive entrant's new service could have caused some of the defections, so that these customers would be labeled as non-adopters, while they actually adopt the competitor's new service. Apart from the fact that there is no data available on this issue, we believe it is justified to label these customers as nonadopters, as we specifically investigate the adoption of the focal company's new service among existing customers.

iv These estimation results can be requested from the first author.

${ }^{v} \mathrm{We}$ also did an additional analysis to further assess potential long-term effects of our included marketing communications, where we considered the cumulative effects of advertising expenditures for all four types of marketing communications using the approach of Nerlove and Arrow (1962). Our estimation results did not reveal any cumulative effects for service- and brand advertising of the focal supplier, service advertising of competitors. We found an unexpected positive effect of cumulative competitive brand advertising. Given the absence of strong support for cumulative advertising effects, we do not report these effects in the paper.
\end{abstract}




\section{Publications in the Report Series Research ${ }^{*}$ in Management}

\section{ERIM Research Program: "Marketing"}

2007

Marketing Communication Drivers of Adoption Timing of a New E-Service Among Existing Customers Remco Prins and Peter C. Verhoef ERS-2007-018-MKT

Indirect Network Effects in New Product Growth

Stefan Stremersch, Gerard J. Tellis, Philip Hans Franses and Jeroen L.G. Binken ERS-2007-019-MKT

A complete overview of the ERIM Report Series Research in Management: https://ep.eur.nl/handle/1765/1

ERIM Research Programs:

LIS Business Processes, Logistics and Information Systems

ORG Organizing for Performance

MKT Marketing

F\&A Finance and Accounting

STR Strategy and Entrepreneurship 